\title{
Disulfiram combats cancer via crippling valosin-containing protein/p97 segregase adaptor NPL4
}

\author{
Nan Ding ${ }^{1,2}$, Qianzheng $\mathrm{Zhu}^{2,3}$ \\ ${ }^{1}$ CAS Key Laboratory of Heavy Ion Radiation Biology and Medicine, Institute of Modern Physics, Chinese Academy of Sciences, Lanzhou 730000, \\ China; ${ }^{2}$ Department of Radiology, ${ }^{3}$ James Cancer Hospital and Solove Research Institute, The Ohio State University, Columbus, OH 43210, USA \\ Correspondence to: Qianzheng Zhu. Department of Radiology, The Ohio State University, 1024 Biomedical Research Tower, $460 \mathrm{~W} 12$ th Avenue, \\ Columbus, OH 43210, USA. Email: zhu.49@osu.edu. \\ Comment on: Skrott Z, Mistrik M, Andersen KK, et al. Alcohol-abuse drug disulfiram targets cancer via p97 segregase adaptor NPL4. Nature \\ 2017;552:194-9.
}

Submitted Feb 28, 2018. Accepted for publication Mar 14, 2018.

doi: $10.21037 /$ tcr.2018.03.33

View this article at: http://dx.doi.org/10.21037/tcr.2018.03.33

Disulfiram (DSF), also known as Antabuse, is a Food and Drug Administration (FDA)-approved drug, which has been used for anti-alcoholism in clinic for more than 60 years (1). DSF is a member of the dithiocarbamate (DTC) family, which comprises a broad class of molecules possessing an R1R2NC(S)SR3 functional group that gives the family the ability to complex metals and react with sulfhydryl groups. DSF was originally found to act as an irreversible inhibitor of aldehyde dehydrogenase (ALDH) for anti-alcoholism and is safe with no toxicity (2). Due to the discovery that DSF and its metabolites kill cancer cells and slow tumor growth in animal models $(3,4)$ and human patients $(3,5)$, there has been an effort for repurposing this drug for cancer treatment (6-9). Several potential targets of DSF's action, such as ALDH, NF- $\kappa \mathrm{B}$ and proteasome, etc., were recently found (please see references therein) (10). It appears that DSF can act against a broad spectrum of malignancies, and, it can also target cancer cells with cancer stem cell-like properties. It has been known that the tumor cytotoxic activity of DSF is copper-dependent. The precise mechanisms of DSF's anticancer activity, however, are still unknown. A recent work by Skrott et al. identified valosincontaining protein (VCP)/p97 segregase adaptor NLP4 as new molecular target of DSF (11), providing a new rationale for clinical trials aiming at repurposing this old drug.

NPL4 is one of major substrate adaptors of $\mathrm{VCP} / \mathrm{p} 97$ segregase, which is conserved from yeast to human. The hexameric structure with AAA-type ATPase activity (Figure 1), together with adaptors/cofactors capable of binding to ubiquitinated substrates, enables $\mathrm{VCP} / \mathrm{p} 97$ segregase to impose conformational changes on substrate proteins, and, to pull the ubiquitinated proteins out of membranes, segregate them from their binding partners or extract them from chromatin (12). The cellular function of VCP/p97 segregase is mostly based on its critical role in the ubiquitin-proteasome system (UPS).

The UPS is responsible for degradation of most cellular proteins, and thereby plays a regulatory role in a wide range of cellular processes. Because of UPS's essential role in protein homeostasis, the UPS has been considered as an important target for anticancer drug development. The UPS includes two distinct steps. First, the target proteins are labeled with a minimum four ubiquitin moieties through an E1-E2-E3 cascade enzymatic ubiquitination reaction. Second, the ubiquitin-conjugated target proteins are recognized, unfolded and degraded by $26 \mathrm{~S}$ proteasome. For some of target proteins, it is necessary to be segregated from their binding partners or imbedded cellular structures by $\mathrm{VCP} / \mathrm{p} 97$ segregase, which then presents the target proteins to proteasome for degradation.

It is now known that $\mathrm{VCP} / \mathrm{p} 97$ plays a central role in governing various aspects of protein homeostasis and cellular stress responses (13), including endoplasmic reticulumassociated degradation (ERAD), ribosome-associated quality control, mitochondria-associated degradation (MAD), cytosol degradation and macrophage (12-14). Furthermore, the $\mathrm{VCP} / \mathrm{p} 97-$ mediated extraction is now established as an integral part in fundamental chromatin-related processes 


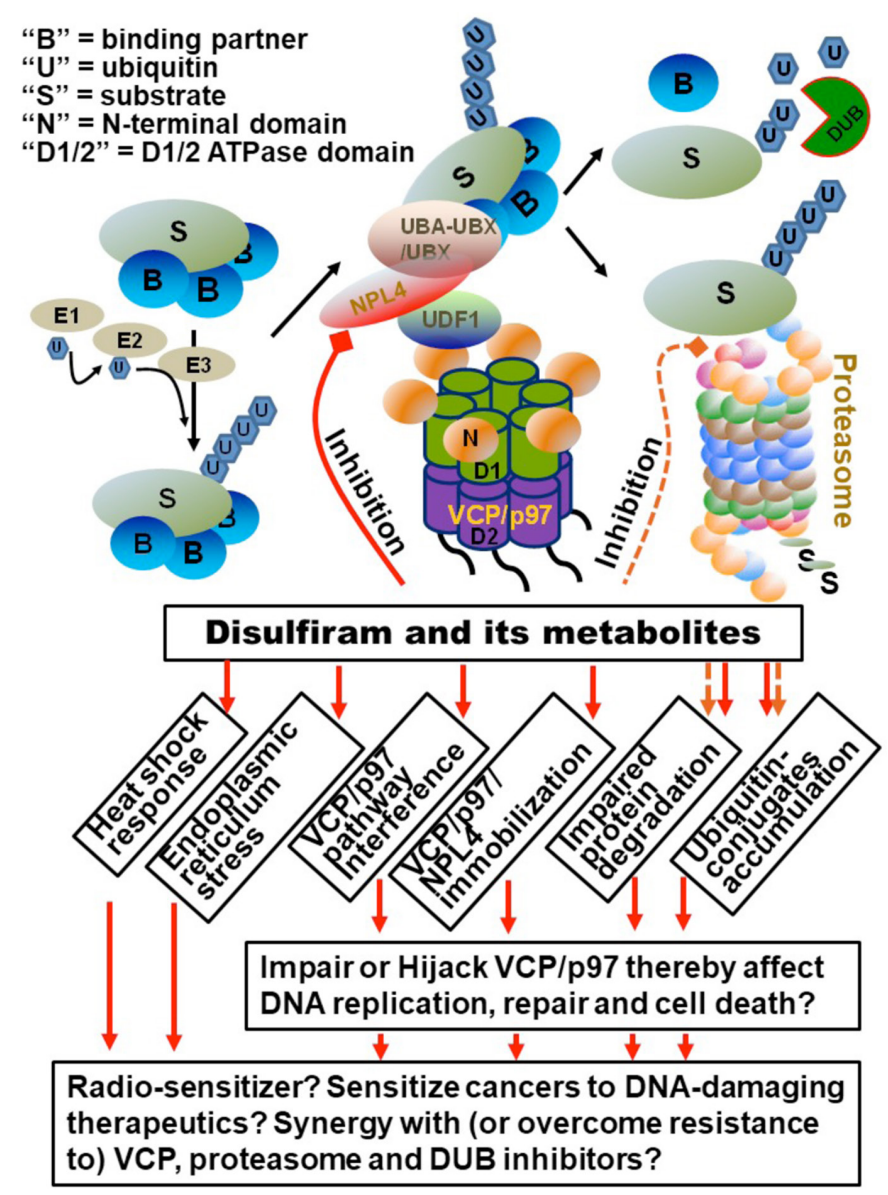

Figure 1 The actions of disulfiram on NPL4 component of VCP/p97 segregase complex in the ubiquitin-proteasome system, the cellular consequences and their implications. The targeted protein substrates are labeled with ubiquitin moieties through an E1-E2-E3 cascade of enzymatic ubiquitination reaction. In VCP/p97-mediated proteolysis, the poly-ubiquitinated substrates are segregated from their binding partners by VCP/p97 segregase and presented to proteasome for proteolysis. Alternatively, the VCP/p97-mediated substrate segregation is followed by non-proteolytic processing and ubiquitin removal by deubiquitinating enzymes (DUBs). Disulfiram acts on NPL4, causes NPL4 clustering/aggregation, and leads to diverse phenotypic features, including heat-stock response, ER stress, ubiquitin stress and accumulation of ubiquitin conjugates, etc. As a result, many cellular functions, such as cell death, DNA replication and DNA repair pathways, may be affected. The mechanism of disulfiram's action has implications in future studies toward repurposing disulfiram as an anticancer drug, including but not limited to the use of disulfiram as radio-sensitizer, in synergy with DNA-damaging therapeutics, proteasome and VCP/ p97 inhibitors, deubiquitinating enzyme inhibitors, or to overcome drug-resistance of cancer cells to proteasome inhibitors. VCP, valosincontaining protein; DUB, deubiquitinating enzyme; ER, endoplasmic reticulum.

(15), such as DNA replication (16), DNA damage response (17), double-strand break repair $(18,19)$, DNA cross-link repair (20) and nucleotide excision repair $(21,22)$. These $\mathrm{VCP} / \mathrm{p} 97$ functions provide a rational understanding of the diverse phenotypic feathers (Figure 1), as described by Skrott et al. (11), when NPL4 function is impaired or poisoned by DSF's metabolite, DTC-copper complex [bis (diethyldithiocarbamate)-copper (CuET)].
As a member of the largest family of $\mathrm{VCP} / \mathrm{p} 97$ substrate adapters characterized by ubiquitin regulatory $\mathrm{X}$ (UBX) and UBX-like (UBXL) domain (12), NPL4 contains a N-terminal UBXL domain, and additional NPL4 conserved domain, C-terminal NPL4 zinc finger (NZF) domain as well as a putative zinc finger-NPL4 (ZF-NPL4) domain. The NZF of NPL4 protein is capable of binding to polyubiquitin, while both NPL4 conserved and ZF-NPL4 
domains mediate the interaction with UDF1 (23). The NPL4-UDF1 complex binds to the aminoterminal (N-terminal) domain of $\mathrm{VCP} / \mathrm{p} 97$, forming a VCP/p97-UFD1-NPL4 core complex, which works together with other adaptors to act in the UPS.

Given the critical function of VCP/p97-UFD1-NPL4 complex in the UPS, it is not a surprise that some CuETinduced phenotypic features share with proteasome inhibitors, including accumulation of cellular polyubiquitin conjugates, diminution of ubiquitin-histone (uH2A) due to ubiquitin stress, cytoplasmic accumulation of poly-ubiquitinated proteins. Notably, it was previously reported that DSF and/or its metabolite was able to directly inhibit proteasome activity (24). Nonetheless, Skrott et al. demonstrated that CuET can target NPL4 at much lower concentration, which does not significantly affect ubiquitinindependent 20S-proteasome-mediated degradation. CuET acts on NPL4 through interacting the ZF-NPL4 domain and immobilizes NPL4, resulting in prominent nuclear, and to lesser extent, cytoplasmic clustering of NPL4. Consequently, the immobilized NPL4 aggregates trigger heat-shock response (HSR) and endoplasmic reticulum (ER) stress/unfolded protein response (UPR), the distinctive features induced by CuET. The nuclear NPL4 clusters co-localize with small ubiquitin-like modifier (SUMO) 2/3, poly-ubiquitin (lysine 48) and Tar DNAbinding protein 43 (TDP-43), which are typical features of aggregated defective protein. Unusually, VCP/p97 but not NPL4-binding partner UDF1 co-localizes with nuclear NPL4 clusters. The ectopically expressed NPL4 (MUT)GFP with mutated ZF-NPL4 domain similarly forms immobile nuclear clusters spontaneously in untreated cells, reminiscent of events upon CuET treatment. Another CuET-induced distinctive phenotype is HSR, a cellular response caused by aggregation of misfolded or damaged proteins. The CuET-induced HSR is accompanied by nuclear stress foci of heat shock factor 1 (HSF1) and heat shock protein 70 (HSP70) at NPL4 clustering sites. Skrott et al. further suggested that immobilized NPL4 proteins attract ubiquitinated proteins or proteins that subsequently become ubiquitinated and/or SUMOylated. Thus, CuET cripples NPL4 but perhaps keeps it with the capability of binding to some of its protein interactors or ubiquitinated proteins. The identities and the functions of ubiquitinated proteins associated with immobilized NPL4 are yet to be uncovered. Nevertheless, it is attempting to ask whether the homeostasis of these proteins is formerly regulated by VCP/p97-UFD1-NPL4 complex and UPS, or whether the immobilized NPL4 proteins, especially in nucleus, are associated with certain cellular processes.

The phenomena that the poly-ubiquitin conjugates, (SUMO) $2 / 3$ and VCP/p97 accumulate at NPL4 clustering sites while uH2A is diminished due to ubiquitin stress suggests that both ubiquitination cascade and $\mathrm{VCP} / \mathrm{p} 97$ are hijacked for aggregated defective proteins as a result of CuET-induced NPL4 clustering. It was previously reported that accumulation of poly-ubiquitinconjugated polyglutamine disease protein aggregates, associated with Huntington's disease, not only causes $\mathrm{uH} 2 \mathrm{~A}$ deubiquitination, nuclear ubiquitin depletion, but also results in a functional VCP/p97 deficiency due to the sequestering of $\mathrm{VCP} / \mathrm{p} 97$ by poly-ubiquitinconjugated polyglutamine disease proteins. Consequently, the functional VCP/p97 deficiency leads to impaired double-strand DNA break repair (25). Thus, another question raised by the CuET-induced phenotypic features is whether VCP/p97 and other ubiquitin adapters are sequestered by NPL4 aggregates? What are cellular proteins and functionalities, e.g., DNA repair, affected?

Another interesting phenomena described by Skrott et al. is the higher CuET concentration in cancer cells. It is previously documented that the DSF-copper complex is highly cytotoxic to cancer cells but not damage normal cells (10). The CuET enrichment in cancer cells may explain the selective cytotoxicity of DSF to cancer cells.

The findings by Skrott et al. as mentioned in above, offer a new rationale for repurposing DSF for cancer therapy. Since the VCP/p97 segregase complex is involved in a variety of cellular functions, the findings may open a wide window to gain better insight into how DSF may be used in clinical trials or translational studies in future (Figure 1). For example, tests of DSF as radio-sensitizer can be based on the role of $\mathrm{VCP} / \mathrm{p} 97$ UFD1-NPL4 in double-strand break repair (17-19). Similarly, trials of combinational use of DSF with DNAdamage therapeutics such as platinum and Et-743 can be rationalized by the role of VCP/p97-UFD1-NPL4 in nucleotide excision repair $(21,22)$ and DNA cross-link repair (20). Because VCP/p97-UFD1-NPL4 functions cooperatively with proteasome in UPS, examinations of the synergistic anticancer effect of DSF, with inhibitors of proteasome, $\mathrm{VCP} / \mathrm{p} 97$, deubiquitinating enzymes and even PARP, are expected to undertake. The more specific functions of VCP/p97-UFD1-NPL4 are emerging, the 
more tests of potential applications of DSF would be warranted in future clinical and translational studies.

\section{Acknowledgments}

Funding: Our work on VCP/p97's functionality in nucleotide excision repair was supported by National Institute of Health grants ES012991 (to Q Zhu).

\section{Footnote}

Provenance and Peer Review: This article was commissioned and reviewed by the Section Editor Chen Qian (Center for Inflammation \& Epigenetics, Houston Methodist Hospital Research Institute, Houston, TX, USA).

Conflicts of Interest: Both authors have completed the ICMJE uniform disclosure form (available at http://dx.doi. org/10.21037/tcr.2018.03.33). The authors have no conflicts of interest to declare.

Ethical Statement: The authors are accountable for all aspects of the work in ensuring that questions related to the accuracy or integrity of any part of the work are appropriately investigated and resolved.

Open Access Statement: This is an Open Access article distributed in accordance with the Creative Commons Attribution-NonCommercial-NoDerivs 4.0 International License (CC BY-NC-ND 4.0), which permits the noncommercial replication and distribution of the article with the strict proviso that no changes or edits are made and the original work is properly cited (including links to both the formal publication through the relevant DOI and the license). See: https://creativecommons.org/licenses/by-nc-nd/4.0/.

\section{References}

1. Hald J, Jacobsen E. A drug sensitizing the organism to ethyl alcohol. Lancet 1948;2:1001-4.

2. Johansson B. A review of the pharmacokinetics and pharmacodynamics of disulfiram and its metabolites. Acta Psychiatr Scand Suppl 1992;369:15-26.

3. Dufour P, Lang JM, Giron C, et al. Sodium dithiocarb as adjuvant immunotherapy for high risk breast cancer: a randomized study. Biotherapy 1993;6:9-12.

4. Valeriote F, Grates HE. Potentiation of nitrogen mustard cytotoxicity by disulfiram, diethyldithiocarbamic acid, and diethylamine in mice. Cancer Res 1989;49:6658-61.

5. Brar SS, Grigg C, Wilson KS, et al. Disulfiram inhibits activating transcription factor/cyclic AMP-responsive element binding protein and human melanoma growth in a metal-dependent manner in vitro, in mice and in a patient with metastatic disease. Mol Cancer Ther 2004;3:1049-60.

6. Iljin K, Ketola K, Vainio P, et al. High-throughput cellbased screening of 4910 known drugs and drug-like small molecules identifies disulfiram as an inhibitor of prostate cancer cell growth. Clin Cancer Res 2009;15:6070-8.

7. Lun X, Wells JC, Grinshtein N, et al. Disulfiram when Combined with Copper Enhances the Therapeutic Effects of Temozolomide for the Treatment of Glioblastoma. Clin Cancer Res 2016;22:3860-75.

8. Pantziarka P, Bouche G, Meheus L, et al. Repurposing drugs in your medicine cabinet: untapped opportunities for cancer therapy? Future Oncol 2015;11:181-4.

9. Pantziarka P, Bouche G, Meheus L, et al. The Repurposing Drugs in Oncology (ReDO) Project. Ecancermedicalscience 2014;8:442.

10. Jiao Y, Hannafon BN, Ding WQ. Disulfiram's Anticancer Activity: Evidence and Mechanisms. Anticancer Agents Med Chem 2016;16:1378-84.

11. Skrott Z, Mistrik M, Andersen KK, et al. Alcohol-abuse drug disulfiram targets cancer via p97 segregase adaptor NPL4. Nature 2017;552:194-9.

12. Xia D, Tang WK, Ye Y. Structure and function of the AAA+ ATPase p97/Cdc48p. Gene 2016;583:64-77.

13. van den Boom J, Meyer H. VCP/p97-Mediated Unfolding as a Principle in Protein Homeostasis and Signaling. Mol Cell 2018;69:182-94.

14. Meyer H, Weihl CC. The VCP/p97 system at a glance: connecting cellular function to disease pathogenesis. J Cell Sci 2014;127:3877-83.

15. Franz A, Ackermann L, Hoppe T. Ring of Change: CDC48/p97 Drives Protein Dynamics at Chromatin. Front Genet 2016;7:73.

16. Bailey R, Priego Moreno S, Gambus A. Termination of DNA replication forks: "Breaking up is hard to do". Nucleus 2015;6:187-96.

17. Meerang M, Ritz D, Paliwal S, et al. The ubiquitin-selective segregase VCP/p97 orchestrates the response to DNA double-strand breaks. Nat Cell Biol 2011;13:1376-82 .

18. van den Boom J, Wolf M, Weimann L, et al. VCP/p97 Extracts Sterically Trapped Ku70/80 Rings from DNA in Double-Strand Break Repair. Mol Cell 2016;64:189-98. 
19. Inano S, Sato K, Katsuki Y, et al. RFWD3-Mediated Ubiquitination Promotes Timely Removal of Both RPA and RAD51 from DNA Damage Sites to Facilitate Homologous Recombination. Mol Cell 2017;66:622-34.e8.

20. Fullbright G, Rycenga HB, Gruber JD, et al. p97 Promotes a Conserved Mechanism of Helicase Unloading during DNA Cross-Link Repair. Mol Cell Biol 2016;36:2983-94.

21. Zhu Q, Wani AA. Nucleotide Excision Repair: Finely Tuned Molecular Orchestra of Early Pre-incision Events. Photochem Photobiol 2017;93:166-77.

22. He J, Zhu Q, Wani G, et al. UV-induced proteolysis of RNA polymerase II is mediated by VCP/p97 segregase and timely orchestration by Cockayne syndrome B protein. Oncotarget 2017;8:11004-19.

Cite this article as: Ding N, Zhu Q. Disulfiram combats cancer via crippling valosin-containing protein/p97 segregase adaptor NPL4. Transl Cancer Res 2018;7(Suppl 4):S495-S499. doi: $10.21037 /$ tcr.2018.03.33
23. Lass A, McConnell E, Fleck K, et al. Analysis of Npl4 deletion mutants in mammalian cells unravels new Ufd1interacting motifs and suggests a regulatory role of $\mathrm{Npl} 4$ in ERAD. Exp Cell Res 2008;314:2715-23.

24. Chen D, Cui QC, Yang H, et al. Disulfiram, a clinically used anti-alcoholism drug and copper-binding agent, induces apoptotic cell death in breast cancer cultures and xenografts via inhibition of the proteasome activity. Cancer Res 2006;66:10425-33.

25. Fujita K, Nakamura Y, Oka T, et al. A functional deficiency of TERA/VCP/p97 contributes to impaired DNA repair in multiple polyglutamine diseases. Nat Commun 2013;4:1816. 